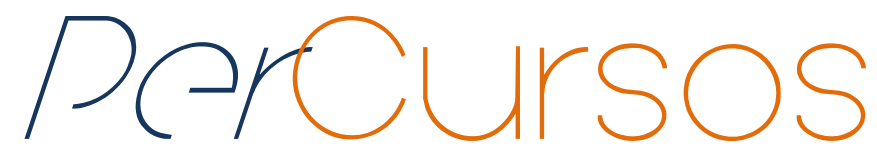

\title{
A potência do precário: restos curriculares em Leona Assassina Vingativa
}

\begin{abstract}
Resumo
Leona Assassina Vingativa, série que se tornou webhit, engendra-se como narrativa menor e dispara questões curriculares por outros modos de produção de subjetividades. Suas composições se valem do procedimento da bricolagem, que trata de inventar, a partir das formações culturais em circulação, uma arte produzida pelos sujeitos ordinários ao manipular improvisações entre tecnologias disponíveis e saberes dominantes, arranjando outros possíveis. Há uma potência do precário em Leona que consiste em equipar-se com poucos recursos para deturpar os clichês imagéticos. No ato de brincar, desenvolve um currículo menor como modo de pensar a condição do sujeito infante pela sua própria transformação. Ela brinca com nossas instituições e com nossas máquinas informáticas, produzindo contrassensos. Leona fabrica, por meio da paródia performática, um corpo imagético que consiste no entre-lugar de problematização dos espaços-tempos estabelecidos. Por fim, traçam-se linhas de uma subjetividade bicha que Leona ajuda a cortar e compor pelas tramas das tecnologias de controle combinadas às tecnologias do eu.
\end{abstract}

Palavras-chave: Rede. Currículo. Videografia. Subjetividade. Bicha.

\author{
Alexsandro Rodrigues \\ Doutor em Educação e Professor \\ do Centro de Educação da \\ Universidade Federal do Espírito \\ Santo - UFES \\ xela_alex@bol.com.br
}
Sérgio Rodrigo da Silva Ferreira
Mestrado em Psicologia pela
Universidade Federal do Espírito Santo - UFES
sergiorodrigosf@gmail.com

\section{Jésio Zamboni}

Doutorando em Educação pela

Universidade Federal do Espírito

Santo - UFES

jesio.zamboni@ufes.br

\footnotetext{
Para citar este artigo:

RODRIGUES, Alexsandro; FERREIRA, Sérgio Rodrigo da Silva; ZAMBONI, Jésio. A potência do precário: restos curriculares em Leona Assassina Vingativa. Revista PerCursos. Florianópolis, v. 14, n.27, jul./dez. 2013. p. $304-323$.
}

DOI: $10.5965 / 1984724614272013304$

http: //dx.doi.org/10.5965/1984724614272013304 


\title{
The power of the precarious: remains in curriculum of Leona Assassina Vingativa
}

\begin{abstract}
Leona Assassina Vingativa (Leona Revengeful Murder), a series of videos that became a webhit, engendered as a minor narrative, shoots a series of questions about the curriculum through others modes of production of subjectivity. It's compositions rely on the procedure of bricolage, which comes down to inventing, from circulating cultural formations, an art produced by the ordinary subjects while manipulating improvisations among available technologies and dominant knowledges, creating other possibilities. There is a precarious power in Leona consisting in equip up with few resources to misrepresent imagery cliches. In the act of playing, it develops a minor curriculum as a way of thinking the condition of the infant subject by its own transformation. She plays with our institutions and machines, producing nonsenses. Leona manufactures, by performative parody, an imagetic body consisting of an in-between of questioning the established space-time of subjects. Last, but not least, lines of queer subjectivity have been traced, that Leona helps to cut and build by using plots of control tecnology together with tecnologies of self.
\end{abstract}

Keywords: Curriculum. Videography. Subjectivity. Fag. 
Leona: impossibilidades de capturas curriculares na afirmação de uma vida pública

“É que o saber não é feito para compreender, ele é feito para cortar" (FOUCAULT, 2006b, p. 28). Por não pretendermos coisa alguma compreender, explicar ou refletir, por buscarmos efetuar cortes nos fluxos dos agenciamentos coletivos, interferindo e participando nas produções de modos de vida e enunciação que se fazem mundo afora, nos voltaremos neste ensaio para Leona Assassina Vingativa. Ela nos convoca a olhar, a atentar e a pensar, pela produção de seus vídeos, por meio dos quais se compartilha uma experiência bicha em modos de se expressar e construir signos, as posições de desejo nas tramas imagéticas da internet.

Leona Assassina Vingativa (LEONA, 2009a; 2009b; 2009c) é uma série de três vídeos que circulam pela internet, se revelando como um sucesso midiático, um webhit. São vídeos caseiros, feitos com simples e precárias câmeras digitais. Um bando de gente jovens? crianças? adolescentes? - que se junta e se põe a fazer videografias, ou seja, forja escritas de si pela produção de cenas audiovisuais veiculadas na internet. Não se trata aí de quaisquer vídeos e redes comunicativas, vídeos e redes também estão endereçados. Embora dir-se-ia que são vídeos caseiros, eles não se restringem a um espaço familiar ou privado, pois são cenas do público. Outros bandos espalham o vídeo entre outros, vídeos e gentes. "As partes dois e três do vídeo só existem por causa dos fãs. Eles nos pedem para continuar, nos dão ideias, sugestões. Só por causa deles é que nós somos divas" (Fernando Valle, apud É DO JURUNAS, 2009).

Assim chega Leona que nos arrebata e nos convoca a acompanhá-la pelos vários vídeos nos quais se constrói e se expressa, provocando-nos a também construir e expressar outros modos de vida porque são possíveis de se inventar. Vários vídeos serão compostos a partir e em torno da trilogia, com a presença de Leona, visionando desdobramentos e efeitos. Nesses, Leona se apresenta com seu extenso e marcante nome completo (A BICHA, 2012; DUELO, 2009; LEONA, 2012c; 2013a; 2013b; MEU NOME, 2011), é entrevistada para falar dos seus vídeos, da fama e da vida (ENTREVISTA, 2011; LEONA, 2011f; 2012C; 2012e), faz shows em boates e festas de família (DUELO, 2009; 
LEONA, 2009g; 2012a), bem como chamadas para estes eventos (LEONA, 2009d; 2009e; 2011C; 2011d; 2012d; ULTIMA, 2009), apresenta-se dançando em concursos de miss regionais (LEONA, 2010; 2011b; 2012b), dentre outras performances cidade afora (A BICHA, 2012; LEONA, 2009f; 2012C), anuncia seu retorno no quarto episódio da série (LEONA, 2011e), atua em comercial de empresa (UM TÁXI, 2012a; 2012b), faz propaganda eleitoral (LEONNA, 2012a; 2012b; 2012c), agita na escola (LEONA, 2011a; 2011f), numa série de vídeos que se configuram como um'A Multiplicação Dramática (KESSELMAN; PAVLOVSKY, 1991), um dispositivo grupal que multiplica cenas por ressonâncias de uma original, de maneira a desmontá-la de um enquadre da infância.

Nas possibilidades imaginadas por Leona em seus agenciamentos concretos de experimentação somos convocados a querer ver e ouvir o que ela tem para nos mostrar e dizer em seus processos de composição de si e do mundo. Em algumas de suas artistagens (CORAZZA, 2006), podemos ouvir da personagem a enunciação do seu nome próprio que, em vez de dizer das suas propriedades constituídas de ser, expressa as apropriações do mundo que ela faz com a multiplicidade em seu nome:

Meu nome é Nathy Nathynha Natiê Lohan Di Sabique de Albuquerque Pampequi de la Tustu Any de Bolda. Mais conhecida como Danusa Deysemeri Leona Merisibely de Bolda Alegas Barrii. A mulher jamais falada, a menina jamais igualada. Conhecidíssima como a noite de Paris, poderosíssima como a espada de um samuray. Eu sou apertada como a bacia, eu sou enxuta como a melancia. Tenho dois filhozinhos: um zolhinhudinho, outro barrigudinho. Casei com o dono da Parmalat, virei mamífera: só mamo. Pertenço a família imperial brasileira Órleans Bragança: penetração difícil. (MEU NOME, 2011)

O trio originário de vídeos narra a saga de Leona (2009a; 2009b; 2009c) que, após ser desmascarada por Aleijada Hipócrita como assassina do próprio marido no primeiro vídeo, entra em toda uma série de situações em torno da vingança contra aqueles que querem denunciá-la para a polícia. Leona Assassina Vingativa se inscreve no gênero narrativo dos melodramas das novelas de televisão. Ali as cenas não apenas se desdobram por uma evolução de Leona, mas por volições (DELEUZE, 2006) ou, como se diz das crianças que se agitam e se põem a fazer algo que perturba o espaço bem demarcado da infância no mundo ocidentalizado, por fogo no rabo, formigas no cu. 
Mas ao se situar no gênero de melodramas novelísticos de TV, Leona brinca com suas normas, regras, procedimentos e temas, se pondo em suas bordas para lhe fazer uma crítica como criação (DELEUZE, 1997a). Isso é a vida perpassando as tramas de sentidos que Leona, de modo virótico a nos contagiar e a se espalhar por nós, convocanos a tecer por estranhamentos aos currículos midiáticos. A (in)usualidade se faz, porém, pelo processo de produção amador e precário, como uma brincadeira de criança que ousa desmontar o lugar de infante - aquele que não fala por si - para afirma-se como criança, criante.

O vídeo torna-se um disparador para uma variedade de questões levantadas por diversas linhas que se entrecruzam e que dizem respeito tanto à produção criativa, quanto à difusão de currículos minoritários e à produção de singularização. Somos instigados a pensar os modos em que se constituem as singularidades pelas vias de comunicação em suas complexidades, numa época em que a informação se configura como valor que, muitas vezes, se concretiza em redes descentralizadas entre múltiplas instâncias. Leona, em seus modos de produção, percorre currículos que, ao serem tramados, formam redes complexas de saberes, poderes e subjetivações, o que nos permite pensar a personagem da minoria como força política e "como forma de emergência histórica, que é um problema das tecnologias de visibilidade [...] tanto presente quanto ausente." (BHABHA, 2011, p. 154).

\section{Bricolagem: a potência do precário}

Leona inscreve-se em uma realidade de invenção de narrativas coletivas menores pelo desvelamento do autor em que ser, ver a si e se por a ver tramam agenciamentos coletivos pelos quais se forjam subjetividades e mundaneidades. Compreendemos com Bhabha (2011, p. 109) que o agenciamento artístico “é uma ética interpretativa e uma estética intervencionista que é, ao mesmo tempo, liminar e luminosa". No campo da produção de possíveis, trata-se de elementos não capturáveis por completo, nos limites das palavras e de nossa capacidade para darmos língua aos afetos (ROLNIK, 2011). Intervenção e interpretação estão no cerne da formação de realidades bricoladas que 
implicam numa invenção por meio da apropriação ou roubo de elementos culturais em circulação. Essas bricolagens apresentam-se abertas a novas composições a partir da produção performativa que bricola imagens e linguagens conhecidas com coisas sempre outras, transtornando o reconhecível.

Pode-se entender por bricolagem a operação de produção que espectadores, sujeitos ordinários tocados pela dimensão estética das coisas, desenvolvem diante das aparelhagens de imagens e linguagens (TV, internet, cinema, teatro etc). Os espectadores, ao negociarem e divergirem nos sentidos em jogo, subvertem sua própria condição, tornando-se inventores de signos pelos restos e pedaços de um mundo saturado de informações. Kastrup (2012, p. 141, grifo da autora) vai nos dizer que

Inventar vem do latim invenire, que significa encontrar relíquias ou restos arqueológicos [...]. A invenção não opera sob o signo da iluminação súbita, da instantaneidade. A invenção implica uma duração, um trabalho com restos, uma preparação que ocorre no avesso do plano das formas visíveis. Ela é uma prática de tateio, de experimentação e de conexão entre fragmentos, sem que este trabalho vise recompor uma unidade original [...]. O resultado é necessariamente imprevisível. O mecanismo aqui é de co-engendramento: sujeito e objeto são produzidos, de modo recíproco e indissociável, por práticas cognitivas concretas.

Leona, por meio de suas brincadeiras, passa de espectadora de telenovelas a inventora de um mundo em que vive por cenas. Ela cria outras narrativas no confronto com os comportados currículos noveleiros, desconcertando-os. Neste sentido, a produção de Leona toma para si o procedimento da bricolagem por meio de um reaproveitamento e transformação de gêneros de linguagens e ações audiovisuais previamente estabelecidos, sobretudo de folhetins televisivos. É perceptivo as pistas que evidenciam referências aos trejeitos, às trilhas sonoras, aos temas e aos discursos de personagens femininas protagonistas das novelas de TV, em especial às vilãs, apresentadas ali satirizadas com reminiscências às produções melodramáticas latinoamericanas.

Como nos fala Certeau (1994), os consumidores ordinários, nos usos das mais diferentes tecnologias, desenvolvem nas relações com as estruturas de poder, como formigas, criações subjetivas e culturais, espaços de liberdade e também de improviso. 
Com isso, fazem "bricolagem com e na economia cultural dominante, usando inúmeras e infinitesimais metamorfoses da lei, segundo seus interesses próprios e suas próprias regras" (CERTEAU, 1994, p. 40). A partir daí, o improviso pode ser pensado como arte do fraco, em suas táticas de manipulação do tempo e do lugar, aproveitando a oportunidade aberta na ocasião/acontecimento pelas forças que lhe são estranhas.

Há, em Leona, uma estética de realismo amador, uma despreocupação com técnicas de excelência da produção. Toma-se a precariedade de recursos que podem equipar os indivíduos na atualidade para produção de suas narrativas não como empecilho para a produção em questão. A primazia da técnica na era da informática permite a produção e circulação de um contingente infinito de imagens e linguagens infestadas de clichês facilmente legíveis e reconhecíveis. A precariedade dos vídeos de Leona é signo da potência de criação de sentidos pela deturpação dos clichês imagéticos. Sob a infinitude das imagens da televisão, com suas comunicações ordenantes, nos vídeos analisados, "haveria algo como o silêncio, ou como a gagueira, ou como o grito, algo que escorreria sob as redundâncias e as informações, que escorraçaria a linguagem, e que apesar disso seria ouvido" (DELEUZE, 1992, p. 56).

Câmeras de vídeo amadoras de baixa resolução, imagens tremidas, ruídos de som e imagem, grandes planos-sequência e ângulos não usuais são indícios de um modo de expressão situado numa zona de marginalidade estética, econômica e social, que revela mais que espontaneidade e preocupação única do registro da cena. Não submetendo a produção videográfica aos modelos e exigências das grandes produções cinematográficas, trata-se de buscar a potência do vídeo para além da tecnocracia e da roteirização como planejamento bem controlado a executar. Com isso, fica evidente a presença do dispositivo de criação das imagens nos rastros de filmagem.

A presença da "equipe" nas imagens e as poucas, mas marcantes, intervenções de edição do vídeo explicitam o processo de produção das cenas, ao invés de procurar escondê-lo, desmontando a relação audiovisual que procura apagar os bastidores para provocar a sensação de realismo da cena. O realismo em Leona se realiza pela transparência da produção e na revelação de alguns dos seus mecanismos. 
Consequentemente, cria-se um aspecto de real, não da história narrada em si mesma, mas dos sujeitos criando o material audiovisual como uma brincadeira.

\section{A brincadeira como linha de fuga}

A produção vai ao encontro das ações do brincar, torna-se o registro de uma charla crível e pregnante ao espectador. Dessa forma, coloca a produção numa relação de jogo de faz de conta imerso em um outro ambiente, que tende a romper as barreiras das esferas pública e privada. A evolução das tecnologias da informação faz com que aconteça uma crescente penetração da esfera privada, em que está o indivíduo comum, na cena pública midiatizada, de maneira que este deixe de ser mero consumidor de imagens e passe a ser "ator de sua própria vida e de seu próprio cotidiano, naquilo mesmo que ele tem de mais corriqueiro e ordinário", requerendo "a visibilidade como uma espécie de direito ou condição almejada de legitimação e reconhecimento" (BRUNO, 2005, p. 56).

Seria preciso, entretanto, considerar a produção de subjetividade em tempos de desenvolvimento vertiginoso dos meios de comunicação. A visibilidade que se obtém com as mídias atuais, como direito e reconhecimento da existência, está intrinsecamente conectada com a formação de uma sociedade de controle (DELEUZE, 1992). Mas, podemos nos perguntar se, em meio à vigilância e ao controle da exposição constante às máquinas de produzir informação, especialmente as de vídeo, não há também uma espécie de contraconduta que as estratégias de controle continuamente tentam modular à medida que resiste a elas. É crucial atentar-se ao fato de que a "estratégia só poderá ser segunda em relação às linhas de fuga, às suas conjugações, às suas orientações, às suas convergências ou divergências [...], pois o desejo está precisamente nas linhas de fuga" (DELEUZE, 1996, p. 20). No caso da infância, tais linhas de fuga constroem o rapto como agenciamento de desejo, como máquina produtora de coletividade.

Pois o rapto, para a criança, é tão temido como desejado; desejado pelo temor mesmo que inspira, pela irrupção que implica na presença rotineira, pela irrupção do estranho e no estranho. [...] Nossa época é indulgente com a fuga, cujos caminhos de regresso conhece e prepara; 
mas, não perdoa o rapto e sua violência irremediável. Sem dúvida, nesta violência é onde nós situamos sua sedução. [...] Entre o rapto e a partida, a vagabundagem, a fuga ou a viagem existe um parentesco evidente. Não há rapto in situ, estático, e nem há fuga que não tenha em vista e antecipe um rapto, nem viagem digna de tal nome que não se coloque sob o signo de um futuro rapto. [...] O rapto impede que a fuga seja uma fuga para nada. E, reciprocamente, a fuga solitária, entre crianças ou por si mesma, não é mais que uma ausência de rapto. Assina com ela seu fracasso e logo volta à sua origem, o local familiar. (SCHÉRER; HOCQUENGHEM, 1979, p. 10-11, grifo do autor, tradução nossa)

De fato, Leona é raptada por sua trupe de atores. É um rapto que desmonta a lógica jurídica sobre a infância, pois ela não se faz vítima, é cúmplice, ou antes, a própria assassina da infância de Estado. "Onde estão os pais desta criança?", "E o conselho tutelar?”, “E a escola?”, “Onde aprendem tudo isso?”, “Cadê o Estado?!”. Leona ri de todas essas indagações com sua gargalhada altiva. Ela é o próprio agenciamento pelo qual uma máquina grupal dispara a fazer shows em boates gays ou festas de família, tanto faz. Em ambos, Leona escandaliza.

A subjetividade em Leona é o meio de vida que ela percorre e constrói como composição coletiva. "A criança não pára de dizer o que faz ou tenta fazer: explorar os meios, por trajetos dinâmicos, e traçar o mapa correspondente" (DELEUZE, 1997b, p. 73). Nesse meio, ela delira os nomes da história, as raças, os continentes, as culturas, aí onde os nomes indicam rastros ou regiões de intensidade (DELEUZE; GUATTARI, 2010). "Sou aliada de Saddan Hussein. Já matei mais de cem.” (LEONA, 2013a; 2013b). Leandro... Leona.... Marla Marluce de Leonça Vis... Nathy Nathynha Natiê Lohan Di Sabike de Albuquerque Pampek de la Tustu Any de Bolda. Mais conhecida como Danuza Deisymary Leona Merisibeli de Bolda Alegas Barri (ENTREVISTA, 2011; A BICHA, 2012; DUELO, 2009; LEONA, 2012C; 2013a; 2013b; MEU NOME, 2011). É variando seus nomes que Leona se apresenta sempre trans, em passagens.

Desta maneira, Leona brinca com nossas instituições e joga com nossas máquinas. O que temos assim é que a brincadeira não só entra na rede mundial de computadores, mas se apropria desta e de seus aparatos para acontecer. A brincadeira com o vídeo em Leona Assassina Vingativa é, antes que um espetáculo, um plano expressivo que se cria às 
voltas com um público indeterminado. Espectadores-participantes são adicionados ao jogo como plateia que ora vaia, ora aplaude, de modo imprevisível. Mas, perpassando as opiniões em senso comum pretendentes a bom senso, a potência de Leona está nos contrassensos que incita deslocamentos do pensar em nós.

\section{O corpo no entre-lugar dos currículos e da cultura}

Sabe-se que o discurso pelo corpo (movimentos, gestos, posições, marcas, vestuários, maquiagem etc) constitui sistemas semióticos que são bastante desenvolvidos. Em Leona, no entanto, vemos o corpo bagunçar o significado estruturado de suas atitudes, socialmente esperadas e consideradas naturais. Por essa via questionase o naturalizado e se coloca em cheque os comportamentos como fontes explicativas do sujeito. Temos uma transubstanciação do esperado em relação aos signos convencionados àqueles corpos, subvertendo os clichês televisivos, criando uma estranheza como conjunto humorístico de sensações.

O binarismo de gênero masculino e feminino é abalado em sua naturalidade pelas brincadeiras de Leona, jogos de criança bicha afeminada, precários em poder e tecnologia, sendo, por isso mesmo, prenhes de potências insuspeitas. O termo bicha refere-se àqueles que apresentam traços, signos de uma posição desejante que não a estabelecida por regras, normas, condutas, maneiras de agir, de dizer, de acordo com o modelo vigente de masculinidade. Nos jogos de poder hegemônicos em nossa sociedade, o estatuto de humanidade vai sendo reiteradamente negado às bichas pelos amoladores de facas, que "destituídos de aparente crueldade, tais aliados amolam a faca e enfraquecem a vítima, reduzindo-a a pobre coitado, cúmplice do ato, carente de cuidado, fraco e estranho a nós, estranho a uma condição humana plenamente viva." (BAPTISTA, 1997, p. 105). Nesse sentido, para além da definição de bicha nos jogos de poder como não-humano, Guattari (1987, p. 35-36) aponta a positividade da bichice em termos de um devir-mulher e um devir-animal: 
Um homem que se desliga das disputas fálicas, inerentes a todas as formações de poder, se engajará, segundo diversas modalidades possíveis, num tal devir mulher. [...] A oposição homem/mulher serve para fundar a ordem social, antes das oposições de classe, de casta, etc. Inversamente, tudo o que quebra as normas, tudo o que rompe com a ordem estabelecida, tem algo a ver com o homossexualismo ou com um devir animal, um devir mulher, etc. Toda semiotização em ruptura implica numa sexualização em ruptura.

A partir de Butler (2010), podemos afirmar que a ruptura do binarismo sexual se desenvolve no âmbito das performances de gênero, ou seja, como construção radical dos atos e das expressividades. Sendo assim, "ser" homem ou mulher é uma questão que se refere às formas de existência que se naturalizam a partir de atos que, ao serem reiterados, acabam por serem tomados como definições de essências dos sujeitos. Em Leona podemos ver como as performances de gênero vão sendo construídas em meio ao desenvolvimento dos vídeos, da capa de um pano qualquer, no primeiro vídeo, passando pela blusa e saia femininas, acompanhadas de lenço na cabeça e óculos escuros no segundo vídeo, até chegar à peruca loira e ao vestido do último vídeo da trilogia. Vamos assim acompanhando a construção do personagem mulher em Leona por meio dos seus atos em cena, cujos índices de composição se podem ver pelas roupas. Ao mesmo tempo, o personagem vai sendo continuamente desmontado pela trama de lutas e violências em que as perucas, óculos e panos vários vão sendo lançados fora junto com as demarcações de gênero. Em meio às naturalizações da sexualidade, a paródia funciona como estratégia de repetição desses atos definidores de maneira a tensioná-los, subvertendo seus sentidos estabelecidos, desvelando seu caráter artificial produzido historicamente. Afinal,

a repetição parodística do gênero denuncia também a ilusão da identidade de gênero como uma profundeza intratável e uma substância interna. Como efeito de uma performatividade sutil e politicamente imposta, o gênero é um "ato", por assim dizer, que está aberto a cisões, sujeito a paródias de si mesmo, a autocríticas e àquelas exibições hiperbólicas do "natural" que, em seu exagero, revelam seu status fundamentalmente fantasístico. (BUTLER, 2010, p. 211, grifo da autora)

Por meio da paródia performática, a produção de Leona constrói um corpo imagético de bichinha da internet. Nesse empreendimento de si, exercícios de 
negociações permanentes (entre eu e o outro) com a cultura vivida e produzida nas redes de conhecimentos desejantes desfazem as fronteiras disciplinares, bagunçam as categorias de classe, de gênero e de raça. Isso nos faz perceber que existem entradas e incursões não conhecidas, um entre que é mais que margem abjeta para a constituição negativa do sujeito da modernidade, é também o lugar de produção de subjetividades, discursos e poderes dissidentes.

O abjeto designa aqui precisamente aquelas zonas "inóspitas" e "inabitáveis" da vida social, que são, não obstante, densamente povoadas por aqueles que não gozam do status de sujeito, mas cujo habitar sob o signo do "inabitável” é necessário para que o domínio do sujeito seja circunscrito. (BUTLER, 1999, p. 155, grifo da autora)

Esse entre-lugar da cultura, como nos diz Bhabha (1998), ao ser praticado nas fronteiras de nós mesmos, permite-nos ver de novo o já visto e estranhar o que aparentemente nos era íntimo, compreendendo, ainda que parcialmente, a fragilidade do outro e do eu da cultura. Pensamos Leona como nó e rasgo presentes na trama das redes curriculares. O currículo é um campo movediço e movente da cultura. A partir de Foucault (2006a,2009), diz-se que o currículo é um lugar para o exercício e a circulação do poder. O currículo é lugar de governo daquilo que se deve saber para disciplinar, controlar e punir. Popkewitz (1994, p. 186) afirma que o currículo "é uma imposição do conhecimento do ‘eu’ e do mundo que propicia ordem e disciplina aos indivíduos”. Pelo currículo costuramse, conectam-se, ligam-se, tecem-se, destecem-se e retecem-se as morais e as éticas. Com esses fios, nós, discursos, tecnologias e dispositivos circulando pelas redes de conhecimentos torna-se possível produzir o homem, o indivíduo, a bicha, o sujeito cultural e a episteme que passam pelas políticas de governo da população e do eu, tendo no seu domínio a preferência pelas fronteiras disciplinares e suas generalizações, assim como as modulações contínuas e permanentes dos comportamentos, pensamentos e disposições dos sujeitos. 


\section{Subjetividade bicha}

Larrosa (2002), procurando prosseguir os trabalhos de Michel Foucault ao interessar-se pelos dispositivos que, tomando por referência a perspectiva que tenta fixar o centro e as margens (excêntricos), agenciam a produção do sujeito e do saber, problematiza os dispositivos binários que produzem, medeiam e governam a experiência. Larrosa nos ajuda a pensar o sujeito enredado às tecnologias de dominação combinadas às tecnologias do eu. Larrosa destaca quatro tecnologias que funcionam em redes constituídas por fios subjetivantes que se tramam no exercício do sujeito sobre si mesmo: as óticas, as discursivas, as jurídicas e as práticas. Essas tecnologias enredam-se com fios morais e éticos tramando subjetivações na experiência e no exercício de si como constituição de sujeito.

$\mathrm{Na}$ constituição de sujeitos de experiências bichas, os dispositivos óticos constroem um campo de visão que dá visibilidade ao sujeito, construindo-o. Leona, pela produção videográfica, constrói-se como sujeito. As imagens compõem um jogo pelo qual ela vai se forjando não apenas como personagem de uma precária paródia novelística, mas como bichinha videográfica, inscrita pelo vídeo que se espalha. Conectam-se a essas linhas de visibilidade, os fios discursivos que o sujeito enuncia sobre si, de maneira não a descrever-se como algo dado a conhecer, mas como atos de fala que provocam transformações incorpóreas. Deleuze e Guattari (1995, p. 19), discutindo a dimensão incorpórea das enunciações, incorporadas aos corpos, apontam que

Os corpos têm uma idade, uma maturação, um envelhecimento; mas a maioridade, a aposentadoria, determinada categoria de idade, são transformações incorpóreas que se atribuem imediatamente aos corpos, nessa ou naquela sociedade. "Você não é mais uma criança...": esse enunciado diz respeito a uma transformação incorpórea, mesmo que esta se refira aos corpos e se insira em suas ações e paixões. A transformação incorpórea é reconhecida por sua instantaneidade, por sua imediatidade, pela simultaneidade do enunciado que a exprime e do efeito que ela produz.

Leona confunde-se com a personagem e, expressando-a, expressa a si própria, não como interioridade absoluta, mas como abertura aos modos de vida coletivos nos quais 
interfere por incorporá-los. Leona só pode confundir-se com sua personagem, quebrando a barreira entre realidade e ficção, por colocar em questão as definições de direitos e de sujeitos. Em vez de tratar-se como margem sem lei e sem norma, Leona inventa normas em modos de vida próprios. As práticas em experimentação pela produção videográfica e vital de Leona são a própria dimensão instituinte da bichinha de internet. São essas dimensões/dispositivos/tecnologias de governo do eu e do outro, tramadas umas com as outras (ver, dizer, julgar, praticar), que nos permitem acompanhar os quereres (sentir, tocar, ouvir, aprender) com Leona. Para Larrosa (2002), essas dimensões nos permitem viver a experiência de si, a temporalização de nossas identificações, de modo a vermo-nos e posicionarmo-nos nesse mundo pela expansão dos modos de vida.

\section{Pode cortar!}

Pela nossa entrada na cena de Leona, na condição de espectadores e críticos (criadores), estabelecemos relações com quem vive e produz redes de conhecimentos. Essas redes são produzidas pelas intervenções nas significações vividas com o outro em meio às tecnologias que são os meios dessa produção. Ao problematizar as significações vigentes, esses currículos menores praticados pelos sujeitos ordinários, contribuem para uma determinada experimentação de si na produção de subjetividades desviantes. Nesse sentido, a experiência de si não é uma prática individualizada, essencializada e naturalizada, ela é produzida pelas tecnologias do eu, que se conectam aos usos e funcionamentos dos aparelhos midiáticos. A experiência de si é prática atrelada à produção de valores morais e éticos, que se efetiva como forma, conduta, modo e estilização de vida, tecida nas relações de compartilhamento com o outro e com o eu temporalizado em experiências. Sujeito e objeto ali se confundem nas emergências estabelecidas pela experiência.

Larrosa (2002, p. 62) chama nossa atenção para a contingência e historicidade do olhar enfatizando que a função produtiva de subjetividades das máquinas óticas é a de determinar "aquilo que se vê ou se faz ver, e o alguém que vê ou faz ver", por isso o sujeito é uma função da visibilidade, dos dispositivos que o fazem ver e orientam seu 
olhar. Pelos regimes de visibilidades postos em circulação no espaço público da rede, todos se sentem vigiados, por forças que sutilmente se mostram disciplinadoras e controladoras. Basta ver Leona Vingativa no colegio (2011f) para perceber o impasse da expressão de Leona na escola, marcada por tais regimes. Mas há também que se ver e se produzir visibilidades para e por outros meios de existência, como Leona o faz e nos convoca a fazer com seus rasgos nas tramas do poder.

“Pode cortar!” (LEONA, 2009a; 2009b; 2009c).

\section{Referências bibliográficas}

A BICHA rica com seu celular à prova d'água. 26 nov. 2012. Disponível em: <http://youtu.be/UZkf4Cxadgc>. Acesso em: 1 abr. 2013.

BAPTISTA, Luis Antonio dos Santos. A atriz, o padre e a psicanalista: os amoladores de faca. Anuário do laboratório de subjetividade e política, Niterói, n. 3/4, p. 103-109, 1997.

BHABHA, Homi K. O local da cultura. Belo Horizonte: Ed. UFMG, 1998.

BHABHA, Homi K. O bazar global e o clube dos cavalheiros ingleses. Rio de Janeiro: Rocco, 2011.

BRUNO, Fernanda. Quem está olhando? Variações do público e do privado em webblogs, fotologs e reality shows. Contemporânea, Salvador, v. 3, n. 2, p. 53-69, 2005. Disponível em:

<http://www.portalseer.ufba.br/index.php/contemporaneaposcom/article/view/3461/2526 >. Acesso em: 1 abr. 2013.

BUTLER, Judith. Corpos que pesam: sobre os limites discursivos do “sexo". In: LOURO, Guacira Lopes. (Org.). O corpo educado: pedagogias da sexualidade. Belo Horizonte: Autêntica, 1999, p. 152-172.

BUTLER, Judith. Problemas de gênero: feminismo e subversão da identidade. 3. ed. Rio de Janeiro: Civilização Brasileira, 2010. 
BUTLER, Judith. Corpos que pesam: sobre os limites discursivos do "sexo". In: LOURO, Guacira Lopes. (Org.). O corpo educado: pedagogias da sexualidade. Belo Horizonte: Autêntica, 1999, p. 152-172.

CERTEAU, Michel de. A invenção do cotidiano 1: artes de fazer. 9. ed. Petrópolis: Vozes, 1994.

CORAZZA, Sandra Mara. Artistagens: filosofia da diferença e educação. Belo Horizonte: Autêntica, 2006.

DELEUZE, Gilles. Conversações. São Paulo: Ed. 34, 1992.

DELEUZE, Gilles. Crítica e clínica. São Paulo: Ed. 34, 1997a.

DELEUZE, Gilles. Desejo e prazer: carta de Deleuze a Foucault. Cadernos de Subjetividade, São Paulo, n. esp., p. 13-25, jun. 1996.

DELEUZE, Gilles. Crítica e clínica. São Paulo: Ed. 34, 1997 .

DELEUZE, Gilles. O que as crianças dizem. In: DELEUZE, Gilles. Crítica e clínica. São Paulo: Ed. 34, 1997b, p. 73-79.

DELEUZE, Gilles. Prefácio ao livro L'Après-Mai des faunes. In: DELEUZE, Gilles. A ilha deserta: e outros textos. São Paulo: Iluminuras, 2006, p. 357-362.

DELEUZE, Gilles; GUATTARI, Félix. Mil platôs: capitalismo e esquizofrenia, vol. 2. São Paulo: Ed. 34, 1995.

DELEUZE, Gilles; GUATTARI, Félix. O anti-édipo: capitalismo e esquizofrenia. São Paulo: Ed. 34, 2010.

DUELO entre Leona a Assassina Vingativa e Aleijada Hipócrita CuzCuz Funnywear. 14 out. 2009. Disponível em: <http://youtu.be/bNZctLyvICM>. Acesso em: 1 abr. 2013.

É DO JURUNAS o maior fenômeno audiovisual paraense. Diário do Pará, Belém, 5 set. 2009. Disponível em: <http://diariodopara.diarioonline.com.br/N-59331.html>. Acesso em: $1 \mathrm{abr} .2013$.

ENTREVISTA com leona a assassina vingativa.mp4. 1 abr. 2011. Disponível em: <http://youtu.be/GQcf3CBzeHM>. Acesso em: 1 abr. 2013.

FOUCAULT, Michel. A ordem do discurso. 13. ed. São Paulo: Ed. Loyola, 2006a. 
FOUCAULT, Michel. Microfísica do poder. 22. ed. São Paulo: Paz e terra, 2006b.

FOUCAULT, Michel. Vigiar e punir: nascimento da prisão. 36. ed. Petrópolis: Vozes, 2009.

GUATTARI, Félix. Revolução molecular: pulsações políticas do desejo. 3. ed. São Paulo: Brasiliense, 1987.

KASTRUP, Virgínia. Inventar. In: FONSECA, Tania Mara Galli; NASCIMENTO, Maria Lívia do; MARASCHIN, Cleci. (Orgs.). Pesquisar na diferença: um abecedário. Porto Alegre: Sulina, 2012, p. 141-143.

KESSELMAN, Hernán; PAVLOVSKY, Eduardo. A Multiplicação dramática. São Paulo: HUCITEC, 1991.LARROSA, Jorge. Tecnologias do eu e educação. In: SILVA, Tomaz Tadeu da (Org.). O sujeito da educação: estudos foucautianos. 5. ed. Petrópolis: Vozes, 2002, p. 35-86.

LEONA a assassina vingativa 1. 26 abr. 2009a. Disponível em:

<http://youtu.be/ACXFHGanR7w>. Acesso em: 1 abr. 2013.

LEONA assassina vingativa 2. 9 jul. 2009b. Disponível em: <http://youtu.be/Nc4cxludKFk>. Acesso em: 1 abr. 2013.

LEONA A assassina vingativa 3:a aliança do mal. 17 ago. 2009c. Disponível em: <http://youtu.be/XNmEf4-HdMY>. Acesso em: 1 abr. 2013.

LEONA E ALEIJADA EM TERESINA. 28 ago. 2009d. Disponível em: <http://youtu.be/Lnidvs3HvHM>. Acesso em: 1 abr. 2013.

LEONA FRICA vingativa. 21 set. 2009e. Disponível em: <http://youtu.be/x-9loTHEHeo>. Acesso em: 1 abr. 2013.

LEONA a Aassassina Vingativa em THE. 9 out. 2009f. Disponível em: <http://youtu.be/YgJrp1QYVOc>. Acesso em: 1 abr. 2013.

LEONA a assassina vingativa e Dafne a selegada. 23 dez. 2009g. Disponível em: <http://youtu.be/yY9GkYgD5CY>. Acesso em: 1 abr. 2013.

LEONA MISS CAIPIRA 2010 (improviso). 8 maio 2010. Disponível em: <http://youtu.be/SFGdXdYXT8w>. Acesso em: 1 abr. 2013.

LEONA Assassina Vingativa em frente o Colégio Santa Rosa. 21 mar. 2011a. Disponível em: <http://youtu.be/Gd6t_c19mCA>. Acesso em: 1 abr. 2013. 
LEONA assassina vingativa miss mix da FEMUQ 2011. 2 maio 2011b. Disponível em: <http://youtu.be/oAt1/UZn8So>. Acesso em: 1 abr. 2013.

LEONA, Assassina Vingativa \& Aleijada Hipócrita em Fortaleza (CINE BETÃO 20 DE AGOSTO). 3 ago. 2011c. Disponível em: <http://youtu.be/bJleSRWijlY>. Acesso em: 1 abr. 2013.

LEONA ASSASSINA EM FORTALEZA / 20 DE AGOSTO (CINE BETÃO). 10 ago. 2011d. Disponível em: <http://youtu.be/S-Tw-UAz2Rw>. Acesso em: 1 abr. 2013.

LEONA ASSASSINA VINGATIVA 4 - EM SETEMBRO. 24 ago. 2011e. Disponível em: <http://youtu.be/OJQ1NftYixE>. Acesso em: 1 abr. 2013.

LEONA Vingativa no colégio. 21 set. 2011f. Disponível em: <http://youtu.be/uKRy4yovjHI>. Acesso em: 1 abr. 2013.

LEONA Assassina Vingativa Show Cine Betão. 24 maio 2012a. Disponível em: <http://youtu.be/w6SrNxcpedl>. Acesso em: 1 abr. 2013.

LEONA MISS SIMPATIA DO RANCHO 2012. 27 maio 2012b. Disponível em: <http://youtu.be/HKDoTY_mOHM>. Acesso em: 1 abr. 2013.

LEONA Assassina dançando eletromelody em Belém - Pará. 16 jun. 2012c. Disponível em: <http://youtu.be/mrwHgMnjWr4>. Acesso em: 1 abr. 2013.

LEONA EM BRASÍLIA. 23 jul. 2012d. Disponível em: <http://youtu.be/o6vpuZ5CzC4>. Acesso em: 1 abr. 2013.

LEONA assassina vingativa: entrevista BarreChilli. 2 nov. 2012e. Disponível em: <http://youtu.be/Ogy8XMm39nc>. Acesso em: 1 abr. 2013.

LEONA atacando na noite de Belém.... 7 jan. 2013a. Disponível em: <http://youtu.be/QvZWICCeHag>. Acesso em: 1 abr. 2013.

LEONA saindo pra balada em Belem. 26 mar. 2013b. Disponível em: <http://youtu.be/BjH3pUQpYkk>. Acesso em: 1 abr. 2013.

LEONNA Assassina e Vingativa Eleições 1. 2 out. 2012a. Disponível em: <http://youtu.be/DZXdbIZnAg8>. Acesso em: 1 abr. 2013.

LEONNA ASSASSINA E VINGATIVA ELEIÇÕES 2. 2 out. 2012b. Disponível em: <http://youtu.be/Q3553W2EbCl>. Acesso em: 1 abr. 2013. 
LEONNA ASSASSINA E VINGATIVA ELEIÇÕES 3.2 out. 2012c. Disponível em: <http://youtu.be/EoiGOo8Xok8>. Acesso em: 1 abr. 2013.

MEU NOME é Leona!. 27 abr. 2011. Disponível em: <http://youtu.be/dzmkuk12Lsg>. Acesso em 1 abr. 2013.

POPKEWITZ, Thomas S. História do currículo, regulação social e poder. In: SILVA, Tomaz Tadeu da. (Org.). O sujeito da educação: estudos foucaltianos. 5. ed. Petrópolis: Vozes, 1994, p. 173-210.

ROLNIK, Suely. Cartografia sentimental: transformações contemporâneas do desejo. Porto Alegre: Sulina, 2011.

SCHÉRER, René.; HOCQUENGHEM, Guy. Co-ire: album sistemático de la infancia. Barcelona: Anagrama, 1979.

ULTIMA chamada para Leona \& aleijada Em Teresina. 6 out. 2009. Disponível em: <http://youtu.be/GcHjOvJnt3E>. Acesso em: 1 abr. 2013.

UM TÁXI para Paris - 1 ${ }^{\text {a }}$ Parte. 14 mar. 2012a. Disponível em: <http://youtu.be/928elHtd2Cs>. Acesso em: 1 abr. 2013.

UM TÁXI para Paris - $2^{\text {a }}$ Parte. 20 mar. 2012b. Disponível em: <http://youtu.be/5dFRCssXII>. Acesso em: 1 abr. 2013. 
